\title{
DIAGNÓSTICO MULTIDISCIPLINAR DA EDUCAÇÃO AMBIENTAL NO ENSINO MÉDIO BRASILEIRO: APLICAÇÃO DE INDICADORES DE DESEMPENHO EM UMA ESCOLA DE NITERÓI (RJ).
}

\section{MULTIDISCIPLINARY EVALUATION OF ENVIRONMENTAL EDUCATION IN THE BRAZILIAN BASIC EDUCATION SYSTEM: A CASE STUDY IN A NITERÓI CITY HIGH SCHOOL}

\author{
Luiz Octávio Gavião ${ }^{1}$ e Gilson Brito Alves Lima ${ }^{2}$ \\ ${ }^{1}$ Mestrando do Programa de Pós-graduação de Engenharia de Produção da Universidade Federal Fluminense - \\ UFF, Niterói - luiz_gaviao@id.uff.br \\ ${ }^{2}$ Professor do Programa de Pós-graduação de Engenharia de Produção da Universidade Federal Fluminense - \\ UFF, Niterói - glima@id.uff.br
}

\section{RESUMO}

Esse artigo é parte dos estudos preliminares para uma dissertação de mestrado que objetiva apresentar indicadores de desempenho para escolas de ensino médio do Brasil, por modelagem fuzzy, com a finalidade de diagnosticar o grau de maturidade do ensino da educação ambiental, num contexto holístico da sustentabilidade. Os indicadores de desempenho foram adaptados de um programa Australiano, em vigor desde 2005, tendo seus indicadores e métricas adaptados ao contexto da educação brasileira, com base em entrevistas com especialistas. A proposta foi aplicada em uma escola de ensino médio de Niterói-RJ. Os resultados obtidos indicaram significativa diferença entre o desempenho da educação ambiental em sala de aula e a prática de iniciativas no campus escolar, que evidencia a importância do enfoque multidisciplinar à educação ambiental.

Palavras-chave: educação; ambiental; sustentabilidade; fuzzy; indicadores.

\begin{abstract}
This article is part of the preliminary studies for a master thesis, which aims to present sustainable school indicators, applied to the Brazilian education system, modeled by fuzzy logic. Those performance indicators measure the maturity level of high schools, through a holistic context of sustainability. The performance indicators were adapted from an Australian program, in vigor since 2005. Interviews with subject matter experts (SME) supported the adaptation of indicators and metrics to the Brazilian context. A high school of Niterói city, Brazil, volunteers as a helper to the application of a pilot-test. The results indicated the relevance of a holistic approach of environmental education, within the context of sustainability. The results also showed the importance of practicing initiatives out of the classroom environment.
\end{abstract}

Key words: education; environment; sustainability; fuzzy; indicators.

\section{INTRODUÇÃO}

A educação ambiental tornou-se um tema relevante no cenário nacional a partir da década de 1980 e a legislação brasileira evidencia esse aspecto. Em 1981, a Lei n 6.938 dispôs sobre a Política Nacional do Meio Ambiente, determinando e estendendo a educação 
ambiental a todos os níveis, inclusive a educação da comunidade. Em 1988, a Constituição Federal incluiu no artigo 225 a necessidade de promover a educação ambiental em todos os níveis. Em 1998, os Parâmetros Curriculares Nacionais do Ministério da Educação estabeleceram o "meio ambiente" como tema transversal, com abordagem multidisciplinar. Em 1999, a Lei $n^{\circ}$ 9.795, que institui a Política Nacional de Educação Ambiental, descreve a educação ambiental como "componente essencial e permanente da educação nacional, devendo estar presente, de forma articulada, em todos os níveis e modalidades do processo educativo, em caráter formal e não-formal”. Finalmente, em 2012, a Lei ${ }^{\circ} 12.608$ incluiu a educação ambiental na Lei de Diretrizes e Bases da Educação.

A legislação ambiental de 1981 integrou a expressão "meio ambiente" às perspectivas sociais e econômicas. De fato a Lei ${ }^{\circ} 6.938$ não abordava o meio ambiente sob o abrangente conceito de desenvolvimento sustentável, um conceito multidisciplinar que seria globalmente debatido nas Conferências sobre o Meio Ambiente de 1987 (Comissão Brundtland) e 1992 (Rio-92). Mesmo assim, o primeiro objetivo da Política Nacional do Meio Ambiente dessa lei descreve a necessidade de "compatibilização do desenvolvimento econômico-social com a preservação da qualidade do meio ambiente e do equilíbrio ecológico" (grifo nosso). Esse objetivo relaciona explicitamente o meio ambiente como parcela do "tripé" da sustentabilidade, que se equilibra entre a preservação ambiental, a responsabilidade social e a viabilidade econômica de uma atividade, processo ou projeto (COMISSÃO BRUNDTLAND, 1991).

A necessidade de abordagem multidisciplinar da educação ambiental também se encontra materializada na Lei $\mathrm{n}^{\circ}$ 12.608, de 2012, que altera a Lei $\mathrm{n}^{\circ}$ 9.394, de 1996 (Lei de Diretrizes e Bases da Educação), estabelecendo que "os currículos do ensino fundamental e médio devem incluir os princípios da proteção e defesa civil e a educação ambiental de forma integrada aos conteúdos obrigatórios" (grifo nosso). Desse contexto legal, extrai-se a necessidade de interligar a educação ambiental às demais perspectivas tradicionais da sustentabilidade. A criação, na década de 1980, de uma legislação específica sobre a educação ambiental não garante ao Brasil, especificamente, a certeza do efetivo ensino do tema nas escolas. O país dispõe de significativo marco legal em variados assuntos, cuja efetiva execução impacta, por vezes, em barreiras administrativas e operacionais de regulamentação, implementação e fiscalização.

No escopo das Nações Unidas, a educação ambiental apresenta considerável histórico. A degradação ambiental por ação humana foi o fator motivador para a realização da 
Conferência de Estocolmo, em 1972, reunindo 113 países e 250 organizações governamentais (OG) e não-Governamentais (ONG). A recomendação nº 96 dessa Conferência abordou especificamente sobre a necessidade de estabelecer

um programa internacional de educação sobre o meio ambiente, de enfoque interdisciplinar e com caráter escolar e extra-escolar, que abarque todos os níveis de ensino e que seja dirigido ao público em geral, especialmente ao cidadão que vive nas áreas rurais e urbanas, ao jovem e ao adulto indistintamente, para lhes ensinar medidas que dentro de suas possibilidades, possam assumir para ordenar e controlar seu meio ambiente (grifo nosso) (BRASIL MMA 2014).

Desde então, uma série de eventos promovidos pela ONU e UNESCO se sucederam, com a finalidade de enfatizar a importância da educação em sustentabilidade e fomentar sua inclusão nos sistemas educativos formais e não-formais. Em 1975, a cidade de Belgrado, na Sérvia, sediou o Seminário Internacional de Educação Ambiental; em 1977, Tbilisi, na Geórgia, sediou a Conferência Intergovernamental sobre Educação Ambiental; em 1992, no Rio de Janeiro, a Conferência Rio-92 produziu um documento, denominado "Agenda 21", cujo capítulo 36 se refere especificamente à questão educacional; em 1997, a Conferência de Thessaloniki, na Grécia, elaborou o documento "Educação para o futuro sustentável: uma visão transdicisplinar para uma ação concertada"; em 2002, Johannesburgo, na África do Sul, sediou a Rio+10, onde surge a proposta para a ONU instituir, a partir de 2005, a "Década da Educação para o Desenvolvimento Sustentável 2005-2014 (DEDS)", formalizada meses depois na Resolução $\mathrm{n}^{\mathrm{o}} 254$ da ONU, com a finalidade de implementar o capítulo 36 da Agenda 21 (BELLEN 2005 e BRASIL MMA, 2014).

$\mathrm{Na}$ esfera acadêmica, diversos autores compartilham a importância da educação ambiental de forma multidisciplinar. Segundo Guarim (2002), a educação ambiental se relaciona com a responsabilidade social, pois permite ao indivíduo e à comunidade participar na construção de novos valores sociais e éticos, para conservação e utilização adequada dos recursos naturais. Gama e Borges (2010) destacam a educação ambiental como um processo crítico, participativo e que valoriza o uso sustentável dos recursos naturais, com abordagens ecológicas, sociais, econômicas, políticas e culturais. Castro (2000) enfatiza que a temática ambiental transcende o envolvimento de profissionais como biólogos, geógrafos e ecólogos, entendendo-se a todos os cidadãos, ou melhor, a todos os atores sociais, pois todos estão sujeitos aos efeitos dos problemas ambientais.

No que se refere à inclusão de atividades práticas à educação ambiental na escola, alguns autores ressaltam a relevância do "aprender fazendo", agregando valor à teoria da sala de aula. Medina (2002) destaca que incluir estudantes na execução dos projetos ambientais os 
torna responsáveis pela realização de tarefas concretas relativas ao tema, atuando em equipe e exercitando, na prática, a cooperação e o trabalho coletivo. Segundo Pádua (2000), a participação dos alunos facilita o despertar por assuntos socioambientais, a percepção do dever de contribuir para a conservação ambiental e o comportamento ético-cidadão.

Diante desses aspectos supra mencionados, o artigo traz como objetivo apresentar indicadores de desempenho para escolas de ensino médio do Brasil, com a finalidade de diagnosticar o grau de maturidade do ensino da educação ambiental, num contexto holístico da sustentabilidade. Além de abordar a educação ambiental de forma multidisciplinar, a factibilidade da coleta dos dados na própria escola proporciona ao docente uma ferramenta de inclusão dos estudantes nesse processo de avaliação da escola.

A estrutura do artigo é composta por cinco partes. A primeira parte, introdutória, traz uma abordagem contextual da educação ambiental no país. Na segunda, é apresentada a abordagem metodológica utilizada para o desenvolvimento do estudo. Já na terceira, apresenta-se a pesquisa de campo em uma escola do ensino médio da cidade de Niterói-RJ para a aplicação dos indicadores. Na quarta parte, realiza-se a análise e discussão dos resultados a partir da comparação entre os dados coletados e os índices de maturidade que a escola avaliada poderá atingir, a partir da implementação ou correção das iniciativas adotadas. Na quinta parte, são apresentadas as conclusões da pesquisa.

\section{METODOLOGIA}

O modelo proposto por Gavião e Lima (2013), que apresentaram indicadores de sustentabilidade ao ambiente escolar, modelados por lógica fuzzy, foi contextualizado ao ambiente educacional brasileiro, para posterior aplicação em uma pesquisa de campo em uma escola de ensino médio da cidade de Niterói-RJ. O Esquema 1 apresenta a sequência de etapas e passos dados ao longo do desenvolvimento desta pesquisa.

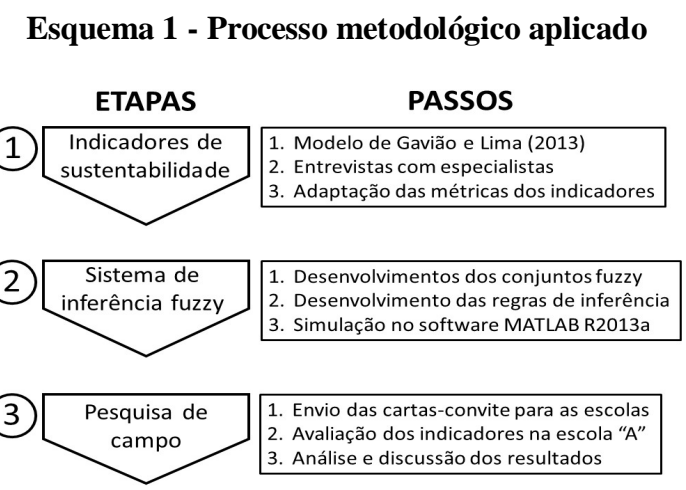

Fonte: os autores 
A primeira etapa se destinou ao levantamento e adaptação dos indicadores de sustentabilidade ao contexto brasileiro. A etapa 1 consistiu de três passos. O passo 1 objetivou a busca do referencial teórico dos indicadores, aplicados em instituições de ensino, o que foi possível através da leitura do modelo de Gavião e Lima (2013). Esse modelo adaptou o programa Australiano desenvolvido em 2005 (DEH 2005 e DET 2010), sendo considerado o benchmark do estudo. O modelo utilizou dados hipotéticos para o teste do sistema fuzzy, sem contextualizar os indicadores ao ambiente educacional brasileiro. O passo 2 envolveu entrevistas presenciais com sete especialistas em meio ambiente, pedagogia, engenharia de produção, engenharia química e política ambiental, com a finalidade de aperfeiçoar os indicadores elaborados no referencial teórico. As entrevistas com especialistas para aquisição de dados de sistemas fuzzy seguiu as orientações de knowledge engineering descritas por KlirYuan (1995) e Cox (1999). O passo 3 definiu as métricas dos indicadores, a partir dos valores das variáveis selecionados nas entrevistas com os especialistas.

A segunda etapa objetivou o desenvolvimento do sistema de inferência fuzzy (SIF), com a finalidade de agregar os dados e produzir os indicadores das diferentes dimensões (educacional, ambiental, social e econômica) e do índice final de sustentabilidade. A etapa 2 consistiu de três passos. O passo 1 transformou os dados coletados nas entrevistas nos conjuntos fuzzy "muito baixo", "baixo", "médio" e "alto", para cada indicador, com funções de pertinência triangulares e trapezoidais. O passo 2 desenvolveu as regras de inferência tipo "se-então", responsáveis pelo funcionamento do sistema fuzzy de entradas e saídas. O número de regras de inferência foi significativamente reduzido a partir do método URC, proposto por Combs (1997), sendo elaboradas 80 regras para os cinco SIF. O passo 3 consistiu no uso do software MATLAB R2013a, com o módulo Fuzzy Toolbox, para compilar o algoritmo de agregação dos indicadores. Os SIF de agregação dos 16 indicadores (IND) foram modelados conforme o Esquema 2, apresentando um aperfeiçoamento do referencial de Gavião e Lima (2013). 
Esquema 2: Sistema de inferência fuzzy

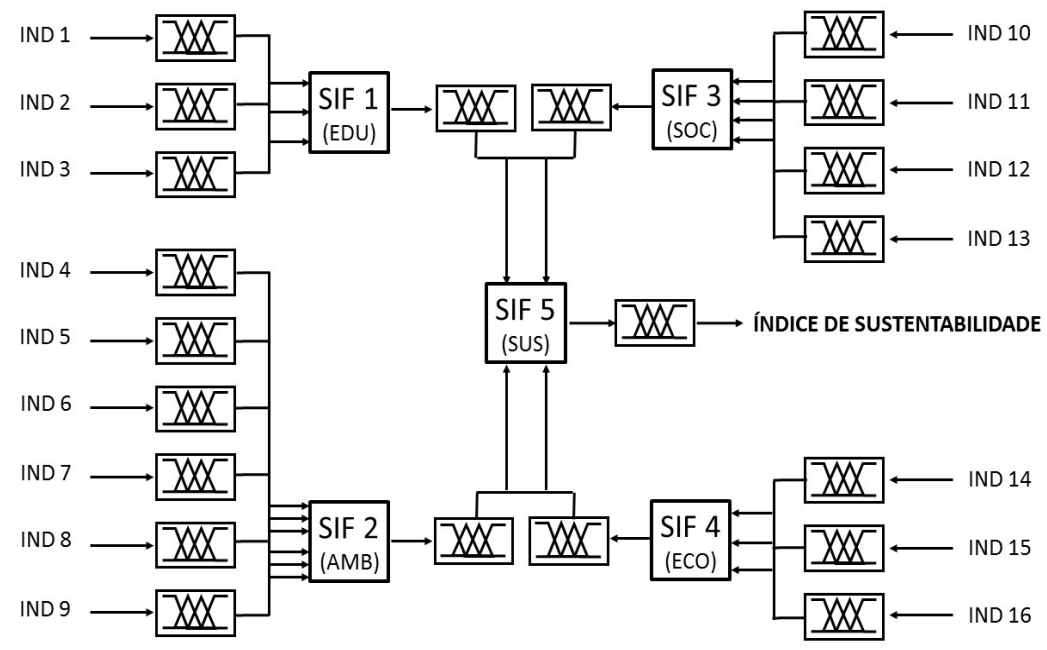

Fonte: Adaptado de Gavião e Lima (2013)

Os SIF da figura 2 demonstram a perspectiva holística do modelo proposto para a avaliação escolar, integrando as dimensões educacional (EDU), ambiental (AMB), social (SOC) e econômica (ECO), cujos resultados são agregados para produzirem o índice de sustentabilidade (SUS) final.

A terceira etapa teve por finalidade a pesquisa de campo para a aplicação dos indicadores em uma escola de ensino médio da cidade de Niterói-RJ. O passo 1 consistiu na elaboração e envio das solicitações de participação para uma amostra aleatória de 20 das 89 escolas da rede de ensino médio do município, com a garantia de confidencialidade das instituições e profissionais entrevistados. O passo 2 envolveu a coleta dos dados dos 16 indicadores. O passo 3 consistiu na análise e discussão dos resultados, conforme exposto a seguir.

\section{PESQUISA DE CAMPO PARA APLICAÇÃO DOS INDICADORES}

A pesquisa de campo, para levantamento e aplicação dos indicadores propostos desenvolveu-se no município de Niterói, tendo a coleta de dados contado com a participação de profissionais de ensino público / privado de estabelecimento escolar do ensino médio, que acolheram a proposta de visita e entrevista destinada a coleta de dados.

Dentre as 20 escolas de Niterói que receberam as solicitações dos autores para o apoio à pesquisa dos indicadores, somente uma escola abriu suas portas à pesquisa, doravante denominada escola "A". De per si, esse aspecto pode denotar certo desinteresse ou descrédito 
pelo tema, de uma cidade de praticamente meio milhão de habitantes, que apresenta elevado índice de desenvolvimento humano (IDH) no país. De uma cidade vizinha ao Rio de Janeiro, que sediou dois dos mais importantes eventos mundiais em meio ambiente, a Rio-92 e a Rio+20, recentemente, os autores alimentaram uma expectativa de maior efetivo de escolas participantes da pesquisa.

Não obstante à reduzida resposta das escolas convidadas, a aplicação da pesquisa na escola "A" foi efetiva e seus resultados foram significativos para a pesquisa. Durante a visita e entrevistas ao diretor, coordenador pedagógico do ensino médio e gerente administrativo da escola, num período aproximado de duas horas, a pesquisa demonstrou sua factibilidade para utilização por docentes e alunos. Os dados coletados na pesquisa constam das tabelas 1, 2, 3 e 4.

Tabela 1 - dimensão educacional da escola "A"

\begin{tabular}{|c|c|c|}
\hline Indicador & Dados & Descrição do indicador \\
\hline Indicador 1 & 1,7 & $\begin{array}{l}\% \text { de profissionais com experiência em sustentabilidade (pontuação de } 0 \% \text { a } \\
100 \% \text { ) }\end{array}$ \\
\hline Indicador 2 & 8,9 & $\begin{array}{l}\% \text { de horas-aula curriculares com temas de sustentabilidade (pontuação de } \\
0 \% \text { a } 100 \% \text { ) }\end{array}$ \\
\hline Indicador 3 & 2 & Eventos acadêmicos anuais de sustentabilidade (pontuação de 0 a 12) \\
\hline
\end{tabular}

Em relação à coleta de dados da dimensão educacional, na escola “A”, verificou-se que o indicador 1 apresentou três professores com formação em ciências da natureza, dentre um universo de 90 professores, com total de 180 funcionários, conformando 1,7 por cento. Quanto ao indicador 2, no ensino médio existem quatro tempos de aulas dentre os 30 semanais que são ministrados ao $1^{\circ}$ ano do Ensino Médio (EM), não há tempos de aula ao $2^{\circ}$ ano e mais quatro tempos semanais são ministrados ao $3^{\circ}$ ano do EM. Dessa forma, oito tempos de aula dentre 90 ministrados ao EM se referem ao meio ambiente, cidadania e bioética, conformando o índice 8,9 por cento. Quanto ao indicador 3, a escola realiza em média um evento por semestre sobre temas do meio ambiente, conformando o índice anual 2. A tabela 2, a seguir, apresenta os resultados da dimensão ambiental, com seis indicadores de desempenho.

Tabela 2 - dimensão ambiental da escola "A"

\begin{tabular}{|l|c|l|}
\hline Indicador & Dados & Descrição do indicador \\
\hline Indicador 4 & 0 & $\begin{array}{l}\% \text { de metas atendidas do Plano de Gestão Ambiental (PGA) (pontuação de } \\
0 \% \text { a } 100 \% \text { ) }\end{array}$ \\
\hline Indicador 5 & 0 & Consultorias e/ou auditorias ambientais na escola (pontuação de 0 a 12) \\
\hline Indicador 6 & 1,5 & $\begin{array}{l}\text { Atividades bem sucedidas na gestão da água (pontuação de 0 a 3, } \\
\text { resultante da soma das atividades 1, 2 e 3) }\end{array}$ \\
\hline
\end{tabular}




\begin{tabular}{|c|c|c|}
\hline Indicador & Dados & Descrição do indicador \\
\hline - Atividade 1 & 1 & $\begin{array}{l}\text { A superação de metas de redução de consumo, com evidente controle e } \\
\text { adoção de medidas para atingi-las e/ou superá-las (pontuação de } 0 \text { a 1) }\end{array}$ \\
\hline - Atividade 2 & 0,5 & $\begin{array}{l}\text { A prática de medidas de conservação, por meio de campanhas de } \\
\text { orientação extensiva a docentes, alunos e staff em geral (pontuação de } 0 \text { a } \\
\text { 1) }\end{array}$ \\
\hline - Atividade 3 & 0 & $\begin{array}{l}\text { Reaproveitamento do recurso natural, como utilização de águas pluviais, } \\
\text { dentre outras tecnologias (pontuação de } 0 \text { a } 1 \text { ) }\end{array}$ \\
\hline Indicador 7 & 1,5 & $\begin{array}{l}\text { Atividades bem sucedidas na gestão de energia (pontuação de } 0 \text { a } 3 \text {, } \\
\text { resultante da soma das atividades } 1,2 \text { e } 3 \text { ) }\end{array}$ \\
\hline - Atividade 1 & 1 & $\begin{array}{l}\text { A superação de metas de redução de consumo, com evidente controle e } \\
\text { adoção de medidas para atingi-las e/ou superá-las (pontuação de } 0 \text { a } 1 \text { ) }\end{array}$ \\
\hline - Atividade 2 & 0,5 & $\begin{array}{l}\text { A prática de medidas de conservação, por meio de campanhas de } \\
\text { orientação extensiva a docentes, alunos e staff em geral (pontuação de } 0 \text { a } \\
\text { 1) }\end{array}$ \\
\hline - Atividade 3 & 0 & $\begin{array}{l}\text { Reaproveitamento do recurso natural, como plantas de energia solar, } \\
\text { dentre outras tecnologias (pontuação de } 0 \text { a } 1 \text { ) }\end{array}$ \\
\hline Indicador 8 & 1 & $\begin{array}{l}\text { Atividades bem sucedidas na gestão de resíduos (pontuação de } 0 \text { a } 3 \text {, } \\
\text { resultante da soma das atividades } 1,2 \text { e } 3 \text { ) }\end{array}$ \\
\hline - Atividade 1 & 0 & $\begin{array}{l}\text { A superação de metas de redução de resíduos, com evidente controle e } \\
\text { adoção de medidas para atingi-las e/ou superá-las (pontuação de } 0 \text { a 1) }\end{array}$ \\
\hline - Atividade 2 & 0 & $\begin{array}{l}\text { A prática de medidas de conservação, por meio de campanhas de } \\
\text { orientação extensiva a docentes, alunos e staff em geral (pontuação de } 0 \text { a } \\
\text { 1) }\end{array}$ \\
\hline - Atividade 3 & 1 & $\begin{array}{l}\text { Adequação do arranjo físico das instalações para facilitar a gestão de } \\
\text { resíduos ou adequá-las às normas vigentes (pontuação de } 0 \mathrm{a} 1 \text { ) }\end{array}$ \\
\hline Indicador 9 & 0,5 & $\begin{array}{l}\text { Atividades bem sucedidas na gestão do solo (pontuação de } 0 \text { a } 3 \text {, } \\
\text { resultante da soma das atividades } 1,2 \text { e } 3 \text { ) }\end{array}$ \\
\hline - Atividade 1 & 0,5 & $\begin{array}{l}\text { A prática do paisagismo (jardinagem), tanto como medida educativa ou } \\
\text { mesmo para urbanização das instalações, com vistas à redução do } \\
\text { consumo em refrigeração de ambientes, dentre outras possibilidades } \\
\text { (pontuação de } 0 \text { a } 1 \text { ) }\end{array}$ \\
\hline - Atividade 2 & 0 & $\begin{array}{l}\text { Iniciativas de reflorestamento ou reinserção de espécies nativas para } \\
\text { recuperar biomas no terreno da escola (pontuação de } 0 \mathrm{a} 1 \text { ) }\end{array}$ \\
\hline - Atividade 3 & 0 & $\begin{array}{l}\text { Prática do plantio alimentar (horta), como projeto educativo ou mesmo } \\
\text { para a alimentação escolar (pontuação de } 0 \text { a } 1 \text { ) }\end{array}$ \\
\hline
\end{tabular}

Em relação à coleta de dados da dimensão ambiental, na escola "A", verificou-se que a escola não possui um PGA e os assuntos relacionados aos aspectos ambientais da gestão de água e energia são centralizados na gerência de administração, por profissional sem especialização ou assessoria em assuntos de sustentabilidade. Assim, a ausência de metas do PGA caracteriza a nulidade do indicador 4. Quanto ao indicador 5, a escola não contrata consultorias especializadas ou recebe auditorias para avaliar o status da gestão ambiental, o que também torna nulo esse indicador.

Quanto ao indicador 6, referente à gestão da água, a soma das pontuações atribuídas às três atividades seguintes compôs o indicador: (1) a gerência de administração realiza o controle de metas de consumo de água a partir dos dados recentes, dos últimos meses, sendo 
atribuído um ponto; (2) as práticas de medidas de conservação são parcialmente realizadas por ocasião das reuniões de gestão, sem haver campanhas específicas (i.e. cartazes, feiras, seminários, outros) para a redução do consumo de água, sendo atribuído meio ponto; (3) a escola não possui sistema de reaproveitamento de águas pluviais ou sistema similar, sem atribuição de pontos. A soma das atividades 1, 2 e 3 conforma o indicador, que recebeu o índice 1,5 .

Quanto ao indicador 7, referente à gestão de energia, a soma das pontuações atribuídas às três atividades seguintes compôs o indicador: (1) a gerência de administração realiza o controle de metas de consumo de energia a partir dos dados recentes, dos últimos meses, sendo atribuído um ponto; (2) as práticas de medidas de conservação são realizadas por ocasião das reuniões de gestão, embora não haja campanhas específicas (i.e. cartazes, feiras, seminários, outros) para a redução do consumo de energia, sendo atribuído meio ponto; (3) a escola não possui sistema de reaproveitamento de energia solar ou sistema similar, sem atribuição de pontos. A soma das atividades 1, 2 e 3 conforma o indicador, que recebeu o índice 1,5 .

Quanto ao indicador 8, referente à gestão de resíduos, a soma das pontuações atribuídas às três atividades seguintes compôs o indicador: (1) a escola não estabelece metas para a redução de resíduos, sem atribuição de pontos; (2) a escola não realiza práticas de conservação para a redução de resíduos, sem atribuição de pontos; (3) a escola possui arranjo físico específico para os resíduos, com portão localizado à retaguarda das instalações e circuito específico, sendo atribuído um ponto. A soma das atividades 1, 2 e 3 conforma o indicador, que recebeu o índice 1.

Quanto ao indicador 9, referente à gestão do solo, a soma das pontuações atribuídas às três atividades seguintes compôs o indicador: (1) a prática de paisagismo é realizada para a melhoria do aspecto de limpeza, embora não explorada de forma educacional ou para a redução de consumo de energia, sendo atribuído meio ponto (2); a escola não realiza iniciativas de reflorestamento ou reinserção de espécies nativas para recuperar biomas no terreno da escola, embora esteja localizada próxima de encostas com mata atlântica nativa, sem atribuição de pontos; (3) a escola não realiza projetos de plantio alimentar, embora possua área disponível e refeitório que atende aos alunos e profissionais da escola, sem atribuição de pontos. A soma das atividades 1, 2 e 3 conforma o indicador, que recebeu o índice 0,5. A tabela 3, a seguir, apresenta os resultados da dimensão social, com quatro indicadores de desempenho. 
Tabela 3 - dimensão social da escola "A"

\begin{tabular}{|l|c|l|}
\hline Indicador & Dados & Descrição do indicador \\
\hline Indicador 10 & 12 & $\begin{array}{l}\text { Parcerias externas anuais com especialistas em sustentabilidade } \\
\text { (pontuação de 0 a 12) }\end{array}$ \\
\hline Indicador 11 & 0 & $\begin{array}{l}\text { Projetos de extensão anuais em sustentabilidade para a comunidade } \\
\text { (pontuação de 0 a 12) }\end{array}$ \\
\hline Indicador 12 & 3 & $\begin{array}{l}\text { Atividades bem sucedidas no relacionamento com o público interno } \\
\text { (pontuação de 0 a 3, resultante da soma das atividades 1, 2 e 3) }\end{array}$ \\
\hline - Atividade 1 & 1 & $\begin{array}{l}\text { A escola realiza pesquisas de satisfação com o público interno, analisa } \\
\text { sugestões e implementa mudanças (pontuação de 0 a 1) }\end{array}$ \\
\hline - Atividade 2 & 1 & $\begin{array}{l}\text { A escola cumpre integralmente a legislação trabalhista e assistencial } \\
\text { relacionada ao público interno (pontuação de 0 a 1) }\end{array}$ \\
\hline - Atividade 3 & 1 & $\begin{array}{l}\text { A escola incentiva oportunidades iguais, gerando emprego para minorias } \\
\text { e portadores de necessidades especiais (pontuação de 0 a 1) }\end{array}$ \\
\hline Indicador 13 & 3 & $\begin{array}{l}\text { Atividades bem sucedidas no relacionamento com o público externo } \\
\text { (pontuação de 0 a 3, resultante da soma das atividades 1, 2 e 3) }\end{array}$ \\
\hline - Atividade 1 & 1 & $\begin{array}{l}\text { Apoio da Comunicação Social em pesquisas e projetos junto ao público } \\
\text { externo, gerando imagem positiva da escola junto à comunidade } \\
\text { (pontuação de 0 a 1) }\end{array}$ \\
\hline - Atividade 2 & 1 & $\begin{array}{l}\text { Apoio de Associações de Pais, Associações classistas e/ou de residentes } \\
\text { locais, indicando uma convivência pacífica e construtiva (pontuação de 0 } \\
\text { a 1) }\end{array}$ \\
\hline - Atividade 3 & 1 & $\begin{array}{l}\text { Apoio da Ouvidoria e/ou Assessoria Jurídica para solucionar conflitos } \\
\text { com o público externo, privilegiando o consenso entre as partes } \\
\text { (pontuação de 0 a 1) }\end{array}$ \\
\hline
\end{tabular}

Quanto ao indicador 10, a escola realiza palestras semanais com especialistas de diversas áreas, incluindo profissionais de sustentabilidade, com a finalidade de apresentar experiências úteis à escolha das futuras carreiras em cursos universitários, sendo atribuída a pontuação máxima de 12 pontos.

Em relação ao indicador 11, a escola realiza projetos sociais junto a instituições carentes e projetos de inclusão social, como o "Abrindo Janelas" para o ensino de informática e o "Corte e Recorte" para ensino de práticas de artesanato e costura, no entanto não aborda temas de sustentabilidade ou mesmo implementa projetos específicos desse contexto. Esse indicador não recebeu pontuação.

Quanto ao indicador 12, referente ao relacionamento com o público interno, a soma das pontuações atribuídas às três atividades seguintes compôs o indicador: (1) escola realiza diagnóstico de "clima organizacional" nas reuniões semanais com os professores e com menor frequência com os funcionários, embora não exista um processo formal e sistemático de coleta de sugestões e críticas, sendo atribuído um ponto; (2) a escola apresenta satisfatório relacionamento com os funcionários, sem o registro de greves ou descumprimento da 
legislação trabalhista, sendo atribuído um ponto; (3) a escola possui cinco funcionários dentre os 180 e diversos alunos com necessidades especiais, caracterizando a preocupação e comprometimento com a inclusão social, sendo atribuído um ponto. A soma das atividades 1 , 2 e 3 conforma o indicador, que recebeu índice 3.

Quanto ao indicador 13, referente ao relacionamento com o público externo, a soma das pontuações atribuídas às três atividades seguintes compôs o indicador: (1) a escola desenvolve atividades de Comunicação Social, tendo como principal veículo a página de internet, com informações atualizadas, sendo atribuído um ponto; (2) a Associação de Pais e Mestres (ASPAM) é atuante e encontra suas atividades divulgadas na página de internet da escola, sendo atribuído um ponto; (3) a escola conta com o apoio de um escritório especializado para a atividade jurídica e atende satisfatoriamente as necessidades da escola, sendo atribuído um ponto. A soma das atividades 1, 2 e 3 conforma o indicador, que recebeu índice 3. A tabela 4, a seguir, apresenta os resultados da dimensão econômica, com três indicadores de desempenho.

Tabela 4 - dimensão econômica da escola "A"

\begin{tabular}{|l|c|l|}
\hline Indicador & Dados & Descrição do indicador \\
\hline Indicador 14 & 0 & $\begin{array}{l}\text { Efetiva aplicação do retorno financeiro bem sucedido na gestão da água, } \\
\text { de energia, de resíduos e do solo (pontuação de 0 a 4, resultante da soma } \\
\text { das atividades 1, 2, 3 e 4) }\end{array}$ \\
\hline - Atividade 1 & 0 & $\begin{array}{l}\text { Projetos de sustentabilidade em água bem sucedidos e se reverteram em } \\
\text { melhorias na própria escola (pontuação de 0 a 1) }\end{array}$ \\
\hline - Atividade 2 & 0 & $\begin{array}{l}\text { Projetos de sustentabilidade em energia bem sucedidos e se reverteram } \\
\text { para melhorias na própria escola (pontuação de 0 a 1) }\end{array}$ \\
\hline - Atividade 3 & 0 & $\begin{array}{l}\text { Projetos de sustentabilidade em resíduos bem sucedidos e se reverteram } \\
\text { para melhorias na própria escola (pontuação de 0 a 1) }\end{array}$ \\
\hline - Atividade 4 & 0 & $\begin{array}{l}\text { Projetos de sustentabilidade em solo bem sucedidos e se reverteram para } \\
\text { melhorias na própria escola (pontuação de 0 a 1) }\end{array}$ \\
\hline Indicador 15 & 0 & $\begin{array}{l}\text { Atividades de captação de recursos externos para projetos de } \\
\text { sustentabilidade (pontuação de 0 a 3, resultante da soma das atividades 1, } \\
\text { 2 e 3) }\end{array}$ \\
\hline - Atividade 1 & 0 & $\begin{array}{l}\text { A escola obtém êxito na aplicação de recursos externos nos projetos de } \\
\text { sustentabilidade (pontuação de 0 a 1) }\end{array}$ \\
\hline - Atividade 2 & 0 & $\begin{array}{l}\text { Os recursos obtidos são efetivamente materializados em melhorias dos } \\
\text { projetos existentes ou criação de novos projetos (pontuação de 0 a 1) }\end{array}$ \\
\hline - Atividade 3 & 0 & $\begin{array}{l}\text { Distribuição desses recursos para projetos de sustentabilidade em água, } \\
\text { energia, resíduos e solo (pontuação de 0 a 1) }\end{array}$ \\
\hline Indicador 16 & 0,5 & $\begin{array}{l}\text { Atividades que evidenciam o comprometimento dos concessionários nos } \\
\text { projetos de sustentabilidade (pontuação de 0 a 3, resultante da soma das } \\
\text { atividades 1, 2 e 3) }\end{array}$ \\
\hline - Atividade 2 & 0,5 & $\begin{array}{l}\text { Os concessionários são formalmente mencionados nos planos de } \\
\text { sustentabilidade, integrando a comunidade acadêmica nesses processos } \\
\text { (pontuação de 0 a 1) }\end{array}$ \\
$\begin{array}{l}\text { Os concessionários cumprem suas metas em sustentabilidade e apresentam } \\
\text { feedback de suas atividades para atendê-las (pontuação de 0 a 1) }\end{array}$ \\
\hline
\end{tabular}




\begin{tabular}{|l|c|ll|}
\hline Indicador & Dados & Descrição do indicador & \\
\hline - Atividade 3 & 0 & $\begin{array}{l}\text { Existência de sanções ou substituição de concessionários que não } \\
\text { cumprem as metas de sustentabilidade (pontuação de 0 a 1) }\end{array}$ & \\
\hline
\end{tabular}

Quanto ao indicador 14, a soma das pontuações atribuídas às quatro atividades seguintes compôs o indicador: (1) não existem projetos de sustentabilidade relacionados ao uso da água, sem atribuição de pontos; (2) não existem projetos de sustentabilidade relacionados ao uso da energia, sem atribuição de pontos; (3) não existem projetos de sustentabilidade relacionados ao uso/recolhimento de resíduos, sem atribuição de pontos; (4) não existem projetos de sustentabilidade relacionados ao uso do solo, sem atribuição de pontos. A soma das atividades 1, 2, 3 e 4 conforma o indicador, sendo portanto nulo.

Quanto ao indicador 15, a soma das pontuações atribuídas às três atividades seguintes compôs o indicador: (1) a escola não capta recursos externos para projetos de sustentabilidade, sem atribuição de pontos; (2) a escola não aplica os recursos externos para projetos de sustentabilidade, sem atribuição de pontos; (3) a escola não distribui os recursos externos nos quatro tipos de projetos de sustentabilidade (água, energia, resíduos e solo), sem atribuição de pontos. A soma das atividades 1, 2 e 3 conforma o indicador, sendo portanto nulo.

Quanto ao indicador 16, a soma das pontuações atribuídas às três atividades seguintes compôs o indicador: (1) não existem PGA ou planos de sustentabilidade e os contratos com os concessionários (cantina e refeitório) são antigos, carecendo de revisão para a inclusão de assuntos de sustentabilidade, sem atribuição de pontos; (2) os concessionários cumprem as normas relativas aos resíduos, no entanto não existem projetos de sustentabilidade que incluam outras atividades (i.e reciclagem, redução de consumo de água e energia, uso de ingredientes naturais da própria escola, dentre outros), sendo atribuído meio ponto; (3) os contratos com os concessionários (cantina e refeitório) são antigos, carecendo de revisão para a inclusão de assuntos de sustentabilidade, sem atribuição de pontos. A soma das atividades 1,2 e 3 conforma o indicador, que recebeu índice 0,5.

\section{DISCUSSÃO DOS RESULTADOS}

De uma maneira geral, a escola "A" apresentou um índice de sustentabilidade em estágio inicial de maturidade, materializado pelo índice 4,46. Os resultados obtidos nos indicadores demonstram que a escola apresenta seu ponto forte na dimensão social, aspecto que corroborou com a opinião das autoridades entrevistadas, sobre o forte viés assistencial da congregação religiosa que administra a escola. Nesse sentido, o índice 6,33 materializa as 
iniciativas sociais implementadas pela escola. Por outro lado, os índices das dimensões ambiental e econômica, atingindo resultados respectivos de 2,58 e 1,19, ancoraram o índice final, prejudicando os melhores resultados das dimensões social e educacional, esse com índice 5,98. O Gráfico 1 apresenta o gráfico com os resultados mencionados.

\section{Gráfico 1: Indicadores da escola "A"}

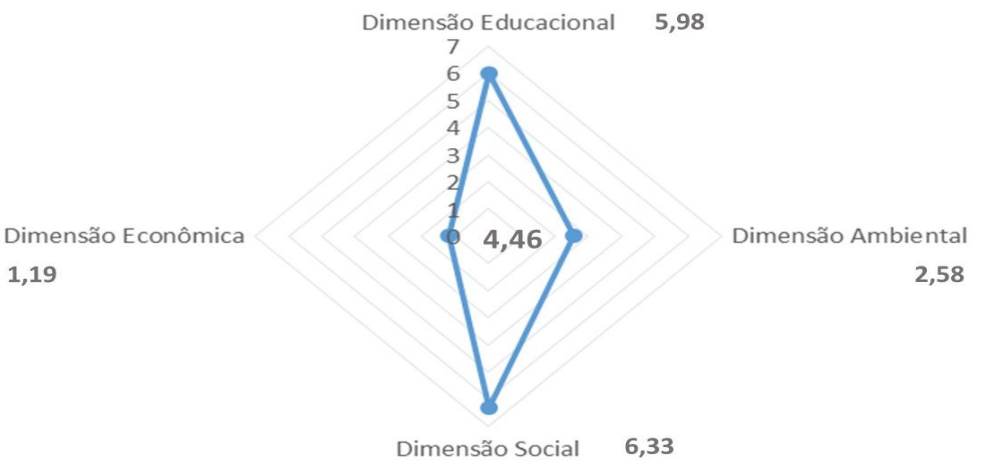

Fonte: os autores

Os indicadores confirmaram a percepção dos autores durante a entrevista, de que a escola realiza diversas medidas de interesse da sustentabilidade, porém não existe um esforço holístico da educação ambiental, sob enfoque de um projeto mais amplo em sustentabilidade. Nesse sentido, o índice final de 4,46 representa uma espécie de "reserva" em potencial para alavancar um projeto consistente no campo da sustentabilidade, porém não evidencia o estágio inicial de um projeto que de fato não existe na escola. A menção da "reserva" de sustentabilidade decorre da existência de profissionais capazes de gerenciar tal projeto, da inclusão de disciplinas afins nos currículos do $1^{\circ}$ e $3^{\circ}$ anos do ensino médio e da preocupação da escola com as causas sociais. Esses recursos em potencial são essenciais para o planejamento, execução e monitoramento de um programa que amplie a teoria da sala de aula para práticas de sustentabilidade na própria escola.

Ainda em relação aos indicadores em conjunto, verifica-se que a escola atende às exigências legais sobre a educação ambiental, tendo em vista o indicador educacional de 5,98. Ao compararmos esse resultado com o da dimensão ambiental, de 2,58, torna-se evidente que a teoria da educação ambiental encontra pouco reflexo no ambiente externo às salas de aula. Um interessante aspecto dos indicadores propostos é justamente agregar um fator de conjunto à educação ambiental, sob o enfoque holístico da sustentabilidade, de forma a apresentar aos 
alunos a prática daquilo que se aprende em sala de aula, facilitando o processo de ensinoaprendizagem.

Quanto à dimensão educacional da escola "A", o indicador 1 pode ser melhorado com o incentivo para que novos professores, mesmo de áreas não relacionadas às ciências da natureza, assim como funcionários da área administrativa, recebam qualificação suficiente para participarem de eventos sobre a sustentabilidade na escola. Dessa forma, os profissionais poderão adquirir conhecimentos interessantes sobre a natureza interdisciplinar da sustentabilidade e propor projetos educacionais que contribuam à formação dos alunos e à melhoria da escola. $\mathrm{O}$ indicador 3 também pode ser aperfeiçoado por meio de feiras de artes com material reciclado, exposições de trabalhos acadêmicos sobre sustentabilidade, exposição de filmes didáticos sobre o tema (i.e. o filme de Al Gore, "Uma verdade inconveniente") ou ciclos de palestras e seminários com especialistas.

Em relação à dimensão ambiental da escola "A", a ausência de um gestor ambiental nas atividades da escola e o acúmulo dessa responsabilidade ao gestor administrativo pode ser um fator contribuinte para os resultados inferiores dos indicadores dessa dimensão. A criação de um PGA, por meio de assessoria externa ou contratação de um profissional, com o intuito de implementar projetos de sustentabilidade nas áreas de água, energia, resíduos e uso do solo poderia trazer economia de recursos para a escola e aproveitamento para atividades práticas de ciências naturais ministradas no ensino médio.

A infraestrutura predial da escola é favorável para a realização de projetos de coleta de águas pluviais, pois os prédios são espacialmente concentrados e possuem considerável área coberta de telhados, úteis para a instalação das calhas de coleta. A região litorânea de mata atlântica, onde se localiza a escola, apresenta significativo regime de chuvas, e um projeto de uso desse recurso renovável pode garantir retorno financeiro e educacional para a escola. A mesma área de cobertura dos telhados permite o uso de painéis solares para compor a matriz energética da escola, com ganho dual financeiro-pedagógico.

Em relação à gestão de resíduos, os tradicionais projetos relacionados aos três "R" (reduzir, reutilizar e reciclar) não apresentam elevada complexidade técnica, por vezes requerem certa dose de criatividade e produzem resultados satisfatórios para a educação em sustentabilidade. A redução do descarte de resíduos sólidos é simples de mensurar, a reutilização de papel de impressão ou banco de livros didáticos para doação é de fácil implementação, assim como a coleta para reciclagem, apenas para ilustrar algumas possibilidades. 
Por fim, o uso do solo para a jardinagem na escola tem explorado somente o aspecto de urbanização, que é relevante e constitui parcela do indicador 9, porém pode também utilizar espaços para o cultivo de mudas de vegetação nativa da mata atlântica, predominante na região onde se localiza a escola (i.e. pau brasil, ipê, copaíba, quaresmeira, paineira, canela, embaúba, dentre outras). Além disso, a existência de um refeitório na escola torna oportuno o cultivo de horta orgânica ou hidropônica, que ocupam reduzido espaço e permitiriam o uso educacional e nutricional.

Quanto à dimensão social da escola "A", os indicadores apresentaram o melhor desempenho. No entanto, ainda é possível melhorá-lo, por meio de projetos de extensão que incluam temas de sustentabilidade. Os profissionais de ciências naturais podem organizar oficinas nos projetos já existentes. No projeto "Corte e Recorte" podem ser reutilizados materiais reciclados ou mesmo explorados materiais oriundos de fibras naturais. No mesmo viés, o projeto "Abrindo Janelas" pode incluir pesquisas e trabalhos sobre a sustentabilidade no ambiente escolar, servindo como fonte para a criação de novos projetos com os alunos.

Por fim, a dimensão econômica da escola "A" apresentou o menor desempenho dentre as demais, representando assim o setor mais urgente para a implementação de aperfeiçoamentos. $\mathrm{O}$ fato de a escola não explorar projetos de sustentabilidade nos recursos água, energia, resíduos e solo torna nulo o indicador 14. Por outro lado, o ambiente escolar é fator relevante e atraente para empresas de outros setores com demandas de investimento em sustentabilidade. Nesse caso, a busca por recursos externos para projetos específicos em sustentabilidade permite a economia de recursos financeiros para a escola com significativo retorno pedagógico. Finalmente, os concessionários precisam figurar no projeto de sustentabilidade, pois contribuem para a imagem da administração junto aos alunos e demais profissionais da escola e também podem auxiliar na educação em sustentabilidade. Uma cantina pode utilizar os produtos orgânicos elaborados na horta escolar, pode explorar projetos de reciclagem de material, dentre outras possibilidades.

De maneira geral, a escola possui elevado potencial para a melhoria do índice de sustentabilidade e as propostas apresentadas nessa análise não esgotam o leque de possibilidades para que os alunos possam verificar na prática aquilo que aprendem na sala de aula. Os indicadores se prestam a esse aspecto, apresentando o status de cada perspectiva interdisciplinar da sustentabilidade, fornecendo subsídios para a tomada de decisão da escola para que o ensino da sustentabilidade possa ser efetivo aos alunos e reverta favoravelmente à gestão da própria escola. A partir desse diagnóstico, uma equipe de profissionais de 
sustentabilidade poderia elaborar um PGA, contendo a missão, visão, metas e prazos para implementar as mudanças sugeridas, bem como uma proposta de reavaliação dos indicadores.

\section{CONSIDERAÇÕES FINAIS}

Este trabalho teve por finalidade apresentar indicadores de desempenho para escolas de ensino médio do Brasil, para diagnosticar o grau de maturidade do ensino da educação ambiental, num contexto holístico da sustentabilidade. De forma simultânea, os indicadores podem ser utilizados de forma acadêmica pelos docentes, para estender o ensino da sala de aula para a prática, dentro do próprio ambiente da escola.

Os indicadores de desempenho foram adaptados de um programa Australiano, em vigor desde 2005, tendo seus indicadores e métricas adaptados ao contexto da educação brasileira, com base em entrevistas com especialistas. Tal adaptação é essencial ao uso dos indicadores, tendo em vista que aquele país apresenta sólido engajamento em projetos de educação ambiental e sustentabilidade, sob contexto diferente do que o Brasil apresenta em termos comparados.

A proposta foi aplicada em uma escola de ensino médio de Niterói-RJ. O município apresenta uma rede de 89 escolas de ensino médio. Os elevados IDH da cidade nos últimos anos e a proximidade física e cultural do Rio de Janeiro, que sediou alguns dos mais importantes eventos mundiais sobre o meio ambiente são fatores que deveriam estimular o engajamento das escolas em prol da educação ambiental. Entretanto, a resposta das 20 escolas selecionadas aleatoriamente para a solicitação da pesquisa foi reduzida a uma escola, denominada escola “ $A$ ' nesse artigo, por necessidade de confidencialidade.

Os resultados indicaram significativa diferença entre o desempenho da educação ambiental em sala de aula e a prática de iniciativas no campus escolar, o que evidencia a importância do enfoque multidisciplinar à educação ambiental. Os indicadores das diferentes perspectivas demonstraram a necessidade de reavaliação da educação ambiental, para que o tema seja aplicado de forma holística e planejada, permitindo que a escola se torne um exemplo aos seus próprios alunos e à comunidade, no que se refere ao respeito ao meio ambiente, à sustentabilidade e à cidadania, conforme constam no marco legal nacional.

\section{REFERÊNCIAS}

Australian Government, Department of the Environment and Heritage (DEH 2005). Educating for a Sustainable Future: a national environmental education statement for Australian schools, Disponível em 
http://www.environment.gov.au/education/publications/pubs/sustainable-future.pdf. Acessado em maio de 2014.

Australian Government, Queensland, Department of Education and Training (DET 2010). Indicators for a Sustainable School, Disponível em <http://www.maroochycatchmentcentre.org.au/catchment/wpcontent/uploads/2010/04/HowSustainable-is-Your-School.pdf. Acessado em maio de 2014.

BELLEN, H. Indicadores de Sustentabilidade: uma análise comparativa. Rio de Janeiro: FGV editora, 2005.

BRASIL. Lei ${ }^{\circ}$ 6.938, de 31 de agosto de 1981. Política nacional do meio ambiente. Disponível em http:// http://www.planalto.gov.br/ccivil_03/leis/L6938.htm. Acessado em junho de 2014.

. Constituição da República Federativa do Brasil de 1988. Disponível em http://www.planalto.gov.br/ccivil_03/constituicao/constituicao.htm. Acessado em junho de 2014.

. Lei $\mathrm{n}^{\circ}$ 9.394, de 20 de dezembro de 1996. Lei de diretrizes e bases da educação nacional. Disponível em http://www.planalto.gov.br/ccivil_03/leis/L9394.htm. Acessado em junho de 2014.

. Lei n ${ }^{\circ}$ 9.795, de 27 de abril de 1999. Política Nacional de Educação Ambiental. Disponível em http://www.planalto.gov.br/ccivil_03/leis/19795.htm. Acessado em junho de 2014.

Lei $\mathrm{N}^{\mathrm{o}} 12.608$, de 10 de abril de 2012. Política nacional de proteção e defesa civil. Disponível em http:// http://www.planalto.gov.br/ccivil_03/_Ato20112014/2012/Lei/L12608.htm. Acessado em junho de 2014.

- Ministério do Meio Ambiente (MMA). Diretoria de Educação Ambiental. Diretório de Documentos sobre a Década das Nações Unidas da Educação para o Desenvolvimento Sustentável. Disponível em http:// http:// http://www.mma.gov.br/port/sdi/ea/deds/. Acessado em junho de 2014.

COMBS, W.E. The Combs method for rapid inference, 1997, Disponível em http://athena.ecs.csus.edu/ hellerm/EEE222/Atricles/Combs_Fuzzy_Logic/Combs_Rapid_Inf erence.htm. Acessado em junho de 2014.

COMISSÃO MUNDIAL SOBRE MEIO AMBIENTE E DESENVOLVIMENTO (COMISSÃO BRUNDTLAND). Nosso Futuro Comum. 2 ed. Rio de Janeiro: FGV editora, 1991.

COX, E. Fuzzy systems handbook: a practioner's guide to building, using, and maintaining fuzzy systems. 2 ed. New York: Academic Press, 1999. 
GAMA, L. U.; BORGES, A.A.S. Educação ambiental no ensino fundamental: a experiência de uma escola municipal em Uberlândia (MG). Revista Brasileira de Educação Ambiental, Brasília, v.5, n.1, p.18-25, 2010.

GAVIÃO, L.O.; LIMA, G.B.A. Educação da Sustentabilidade: uma proposta de indicadores de sustentabilidade escolar por lógica fuzzy. In: XXXIII Encontro Nacional de Engenharia de Produção (ENEGEP). Anais. Salvador, 2013.

GUARIM, V.L.M.S. Barranco Alto: uma experiência em educação ambiental. Cuiabá: UFMT, 2002.

KLIR,G.J.; YUAN,B. Fuzzy sets and fuzzy logic: theory and applications. New Jersey: Prentice Hall, 1995.

MEDINA, N.M. Formação de multiplicadores para educação ambiental. In: PEDRINI, A.G. (org). $O$ contrato social da ciência, unindo saberes na educação ambiental. Petrópolis: Vozes, 2002.

PÁDUA, S.M. A educação ambiental: um caminho possível para mudanças. In: VIANNA, L.P. (Coord.). Panorama da Educação Ambiental no Ensino Fundamental, Brasília: MEC; SEF, 2001. 149p. p. 77-81. (Oficina de trabalho realizada em março de 2000). Disponível em: <http://www.crmariocovas.sp.gov.br/pdf/pol/panorama_educacao.pdf >. Acessado em novembro de 2009. 